\title{
Robert Kastenbaum Responds
}

To the Editor:

I agree with everybody! Melvin Morse wrote: "I am honored to have my research and book Transformed by the Light reviewed by Robert Kastenbaum" (1993, p. 123). What reviewer could disagree with such a handsome response? Morse added the unimpeachable assertion that "Thoughtful criticism is the lifeblood of good research" (1993, p. 123). More substantively, Morse commented that "My only response to Robert Kastenbaum's review . . . is that my research is hypothesisgenerating in nature, and, as such, hopefully will raise questions to be answered by more rigorous projects" (1993, p. 123).

This is a constructive and clarifying statement. In reviewing books or other writings I attempt to evaluate on the basis of the author's own stated objectives. Morse's book succeeds in generating interesting hypotheses, and I said so in my review. However, the book also advanced the claim of having persuasive evidence to present in favor of these hypotheses. I took this claim seriously; to have done other- 
wise would have been to express a lack of respect for the author, and I do not lack respect for the author. In fact, I am much impressed that a practicing physician could find the energy and dedication to carry out this project.

As it happens, the evidence presented in support of the hypotheses was not persuasive. To repeat just one of the criticisms: there are no before-and-after comparisons for the hypotheses regarding the effects of a near-death experience (NDE) on subsequent experiences and actions. There's nothing new, esoteric, or convoluted about this line of criticism. If we don't know what happened at time ${ }_{1}$, how do we know that what's cooking at time ${ }_{2}$ represents a change? The question of causality goes beyond the question of sequence, but without sequence, the questions cannot even be addressed. The other criticisms are likewise straightforward. Again, these criticisms pertain to the relationship between methodology, findings, and conclusions; they do not weigh against Morse's enterprise of generating potentially valuable hypotheses.

Arvin Gibson wrote that "The basic data for study must come from the stories of those who have undergone near-death experiences." I agree with him, too. At least, the basic data must continue to come from the stories unless or until we come up with other illuminating sources of information. I work with stories, too. In my field-communication studies-we call these stories "narratives" and the data they provide are known as "texts." I agree with Gibson and Morse that sometimes the story or narrative is pretty much all we have to shed light on an important question.

This means that we have to make the most of these narratives and texts. By "most" I don't mean suspending the usual principles of scientific research, or bending others to our way of thinking; I mean the most careful attention possible to the narrative process, the textual product, and the dynamic-contextual relationship between the observer-interpreter and both the process and the product. One might think that by now near-death researchers would have made themselves expert in the methodology of narrative process, textual analysis, and reader-text interaction. If anecdotes are mostly what we have, then we should be world-class methodologists in the use of anecdotes, right? I let all readers judge for themselves.

Gibson devoted some of his letter to reviewing Morse's book, my review of Morse's book, and Morse's review of my review; he then proceeded to review his own book. Gibson did not counter any of my specific criticisms with specific arguments. Instead he implied that 
I am rather a spoilsport who is not sufficiently ethereal (though my loyal wife continues to assure me otherwise). He accused me of hankering to replace NDE stories with "some sanitized statistical version of the data [that] would in itself be academically dishonest."

I agree with Gibson that to exclude or distort NDE stories would be academically dishonest; but I wonder what term Gibson would apply to those who believe that they have a privileged understanding of "The Glow of God"? If we already knew the answers, we would not have to wrestle with recalcitrant research problems, monitor our own belief and information processing systems, or concern ourselves with other points of view. We would not have to wonder about the mysteries of existence, but could just join other enlightened folk in basking in the glow.

\section{References}

Morse, M. L. (1993). Review of Transformed by the light and the progress of research [Letter]. Journal of Near-Death Studies, 12, 123-127.

Robert Kastenbaum, Ph.D. Department of Communication Arizona State University Tempe, AZ 85287-1205 